\title{
Inefficient Diversification in Multi-market Oligopoly with Diseconomies of Scope
}

\author{
By Huw David Dixon \\ University of York and CEPR
}

Final version received 18 March 1993.

\begin{abstract}
This paper considers the incentives of oligopolistic firms to diversify into technologically related markets when there are diseconomies of scope. There is a rent extraction incentive for firms to adopt flexible technologies which enable them to enter technologically related markets, thereby increasing competition. However, this strategic motive leads to inefficiency in production owing to diseconomies of scope. This paper shows that the welfare gain arising from increased competition is offset by the inefficiency in production, which may lead to lower welfare than in the case of pure monopoly. This is a counter-example to the contention that the diversification increases social welfare.
\end{abstract}

\section{INTRODUCTION}

It has long been recognized that an important form of potential competition might come from firms already producing in technologically related industries. ${ }^{1}$ We also observe firms diversifying from a particular technological base to produce a wider range of outputs (for example in electronic goods and vehicles). The firm's choice of technology will determine the scope the firms have for this diversification: firms may have a dedicated technology, which is tailor-made for producing one output exclusively, or a flexible $e^{2}$ technology, which allows the firm to produce a range of outputs. This paper models the strategic choice between dedicated and flexible technologies in an oligopolistic context, to determine the incentives for individual firms to opt for flexibility and a wider product range.

One strand of the existing literature on multi-product firms focuses on the role of economies of scope as an explanation of diversification (see e.g. Panzar and Willig 1981; Eaton and Lemche 1991). If we wish to understand why multi-product firms exist in competitive or contestable markets, the explanation will focus on the cost-efficiency of diversified versus single-product firms. The reasons for such economies of scope are related to complementarities of production, 'quasi-public' inputs and related factors. (See Milgrom and Roberts (1990) for a discussion.) However, if we wish to explain the limits to diversification, why a multi-product firm has a particular range of products and not a larger one, one must consider (eventual) diseconomies of scope. Unless it is optimal for one firm to produce all outputs, there must be eventual diseconomies of scope. Indeed, the essence of much of the move to corporate divestiture and 're-focusing' in recent years has been to make efficiency gains by limiting the range of activities undertaken by firms. There are many examples in recent years of firms that have become inefficient as a result of producing too wide a product range (e.g. British Leyland in the mid-1970s-see Murfin 1982-and more recently the Midland Bank in the UK). 
In this paper, I argue that the possibility of over-diversification may be endemic in oligopolistic markets. By diversifying into technologically related markets, firms are able to extract rents from these markets. In the presence of economies of scope, when firms enter each other's markets this may have a beneficial effect on social welfare by leading to increased competition and lower prices (see Brander and Eaton 1984; Calem 1988; Roller and Tombak 1990). However, in the presence of (eventual) diseconomies of scope, there (may) be a social welfare loss in terms of inefficient production to counterbalance the beneficial effects of more competition. This paper presents a model of diversification with diseconomies of scope in which this inefficiency in production actually outweighs the gain from increased competition, resulting in an overall decline in social welfare. The model presented is in many ways specific, and as such might be considered as an example.

\section{The MOdeL}

There are two firms, $i=1,2$, and two markets, $X$ and $Y$. The outputs of each firm $i$ in markets $X$ and $Y$ are $\left(x_{i}, y_{i}\right)$, and the price in market $X$ is given by a linear Cournot inverse demand curve, where without loss of generality we normalize the slope coefficient to unity:

$$
p^{x}=A-\left(x_{1}+x_{2}\right)
$$

and likewise $p^{y}$. Assuming this particular form for the demand curve is a convenient simplification: it would be easy in principle to generalize to allow for the intercept and slope coefficients to differ across markets (as in Calem 1988), or to allow for the two markets to be related with non-zero cross-elasticities of demand (as in Roller and Tombak 1990). ${ }^{3}$ Our assumption allows a particularly simple and clear closed-form solution.

Turning now to the issue of firms' technology, we assume that each firm has a choice between a flexible technology, whichallows it to produce both commodities, and a dedicated technology, which allows it to produce only a single commodity. Furthermore, we will assume that firm 1's 'home' market is $X$ and firm 2's is $Y$, and that for analytical convenience firms can possess the dedicated technology only for their 'home' market. (The results in no way depend on this.) Roller and Tombak (1990) assume that the choice of a flexible technology as opposed to a dedicated technology has no implication for marginal production costs of either output, but has an implication only in terms of fixed costs. However, in this paper we will explore the case where there are diseconomies of scope, so that flexibility may imply a loss of efficiency in terms of marginal cost as well as fixed costs. Dedicated machinery can be tailor-made to suit a particular product, and the firm can accumulate learning-by-doing experience if it specializes in producing only one good. The simultaneous product of two different outputs may raise marginal costs through a loss of learning-by-doing experience, and because production methods cannot be perfectly accommodated to each output. If the firms choose the dedicated technology for their home industry, they incur zero production costs. The idea here is that with a dedicated technology the firm faces zero (constant) marginal cost, any set-up cost $F$ being already incurred and hence sunk. (It is precisely

(C) The London School of Economics and Political Science 1994 
this sunk cost that means that a firm has a 'home' market.) We assume that if a firm wishes to opt for a flexible technology, its joint cost function is given by

$$
C\left(x_{i}, y_{i}\right)=S+c x_{i} y_{i}
$$

This is a special case of the joint cost function used by Eaton and Lemche (1991, p. 902, equn (1)). ${ }^{4} S \geq 0$ is the lump-sum cost of purchasing the flexible technology, for example buying more expensive capital equipment capable of a wider range of operational capabilities, upgrading existing machinery, or investing in training to make the labour force more flexible. $c$ is a coefficient capturing diseconomies of scope as defined by Bulow et al. (1985), ${ }^{5}$ $\partial^{2} C / \partial x_{i} \partial y_{i}=c \geq 0$. Thus, if $c=0$, we have the same (zero) marginal cost as the dedicated technology (as in Roller and Tombak 1990, and Brander and Eaton 1984): a larger $c$ implies that the constant marginal cost of each output is increasing in the output of the other. Note that we are allowing firms to diversify only by adopting a flexible technology: otherwise firms could also enter in the traditional way by purchasing the dedicated technology for the other firm's market at cost $F$. (In this case the entry decision is no different from the standard analysis.)

Useful reference points are the pure-monopoly outcome (each firm remains an undiversified monopolist with its dedicated technology), and the first-best social outcome. Under pure monopoly, firm 1 chooses output $x_{1}$ to maximize profits $x_{1}\left(A-x_{1}\right)$, yielding (analogously for firm 2)

$$
Y^{m}=X^{m}=P^{m}=A / 2: \quad \prod^{m}=A^{2} / 4 .
$$

Given that the dedicated technologies are assumed to be free, the first-best social outcome is clearly to have each firm choosing the dedicated technology, and producing the competitive output $X^{0}=Y^{0}=A$, with both prices at zero. If $S>0$, the flexible technology can never be socially optimal: any combination of outputs can be produced at less cost by two dedicated single-product firms. If we compare the social optimum with the pure-monopoly outcome, the social welfare loss $\left(S W L^{m}\right)$ in each market is given by the welfare-loss triangle $A^{2} / 8$, total loss being $\Delta^{m}=A^{2} / 4$.

\section{Equilibrium AND Technology}

In the case of duopoly with two types of technology, there are three types of outcome possible: (1) where both firms choose the dedicated technology, which gives rise to the standard monopoly outcome in each market; (2) where both firms have a flexible technology, so that there may be mutual entry into each others home markets; (3) the asymmetric case of one-sided entry, where one firm adopts a flexible technology and the other does not.

If both firms have chosen flexible technologies and incurred costs $S$, the variable profits are given for firm 1 (and analogously for firm 2) by

$$
\Pi_{1}(\boldsymbol{x}, \boldsymbol{y})=x_{1}\left(A-x_{1}-x_{2}\right)+y_{1}\left(A-y_{1}-y_{2}\right)-c x_{1} y_{1},
$$

(C) The London School of Economics and Political Science 1994 
where $\boldsymbol{x}=\left(x_{1}, x_{2}\right), \boldsymbol{y}=\left(y_{1}, y_{2}\right)$. This is strictly concave in $\left(x_{1}, y_{1}\right)$ for $c<2$ and yields the first-order conditions:

$$
x_{1}=\frac{A-x_{2}}{2}-\frac{c}{2} y_{1} ; \quad y_{1}=\frac{A-y_{2}}{2}-\frac{c}{2} x_{1} .
$$

If $c=0$, (5) yields the standard reaction functions for duopoly with costless production. If $c>0$, thenthere are diseconomies of scope, which leads to a technological link between the choices of outputs in the two markets. Solving (5) yields $\left(x_{1}, y_{1}\right)$ as a function of $\left(x_{2}, y_{2}\right)$ :

$$
\begin{aligned}
& x_{1}=\frac{A}{2+c}-\frac{x_{2}}{2-\left(c^{2} / 2\right)}+\frac{c y_{2}}{4-c^{2}} \\
& y_{1}=\frac{A}{2+c}-\frac{y_{2}}{2-\left(c^{2} / 2\right)}+\frac{c x_{2}}{4-c^{2}} .
\end{aligned}
$$

Solving for the Nash equilibrium yields the symmetric solution $x_{i}=y_{i}=x^{F}=$ $y^{F} ; p^{x}=p^{y}=p^{F} ; \Pi_{i}=\Pi^{F}$ :

$$
\begin{aligned}
& x^{F}=y^{F}=A /(3+c) \\
& p^{F}=A(1+c) /(3+c) \\
& \Pi^{F}=A^{2}(2-c) /(3+c)^{2}-S .
\end{aligned}
$$

Note that $\Pi^{F}<\Pi^{M}$ : mutual entry leads to lower profits than the monopoly outcome. If $c=S=0$, (7) yields the standard Cournot duopoly with each firm producing $A / 3$ and earning $A^{2} / 9$ in each market. As $c$ becomes larger, the smaller is the equilibrium outputs and profits, and the higher the equilibrium price. It is also useful to note that the equilibrium price-cost margin $\mu$ with mutual entry is:

$$
\mu(c)=\frac{P^{F}-c x^{F}}{P^{F}}=1 /(1+c) .
$$

While equations (7) characterize an equilibrium for $c$ in $[0,2)$, when $c \geq 1$ there is in fact another equilibrium with blockaded monopoly: each firm producing the monopoly output in its own market. To see why, note that if each firm produces $A / 2$ in its home market, there is no incentive for either firm to enter the other's market. This can be verified from (5) when non-negativity constraints on outputs are included. (Note that when $c=1$, a solution to (5) is $x_{1}=y_{2}=A / 2 ; x_{2}=y_{1}=0$.)

In the case that one firm (firm 1, say) opts for a flexible technology and firm 2 has a dedicated technology, there is the possibility of one-sided entry. If $c \geq 1$, there is a blockaded entry into firm 2's home market: it deters entry by producing its monopoly output. For $c<1$, however, there will be equilibrium entry of firm 1 into firm 2's market. The reaction functions and equilibrium outcome in this case are obtained from (5) by setting $x_{2}=0$. The profits the 'raider' firm 1 earn can be denoted by $\Pi^{F r}$ : the raider increases its profits (net of $S$ ) from the monopoly level, so that $\Pi^{F r}+S>\Pi^{M}$. The raided firm will earn less $\Pi^{F-}<\Pi^{M}$. It can be verified that when $S=0, \Pi^{F r}>\Pi^{M}>\Pi^{F}>\Pi^{F-}$. This structure of payoffs is a classic Prisoners' Dilemma, as noted by Roller and 
Tombak (1990). For $S$ small enough, the flexible technology dominates the dedicated technology. Both firms do better by 'co-operating' and earning monopoly profits $\Pi^{M}$. However, each has an incentive to 'defect' by adopting a flexible technology $\left(\Pi^{F r}>\Pi^{M}\right)$ so that in equilibrium both firms earn $\Pi^{F}$, a Pareto-inferior outcome.

\section{Welfare AnAlysis}

In this section we calculate the social welfare loss (SWL) in terms of consumer and producer surplus relative to the first-best in the two symmetric cases: (1) pure monopoly, where both firms choose the dedicated technology and enjoy an uncontested monopoly in their home market, and (2) diversified oligopoly, where both firms opt for flexible technologies and compete in both markets, leading to duopoly. The key point I wish to make is that, with diseconomies of scope, situation 2 can lead to lower social welfare than situation 1.

In the case where both firms choose flexible technologies and diversify, there will be two sources of SWL as depicted in Figure 1, in addition the lump-sum

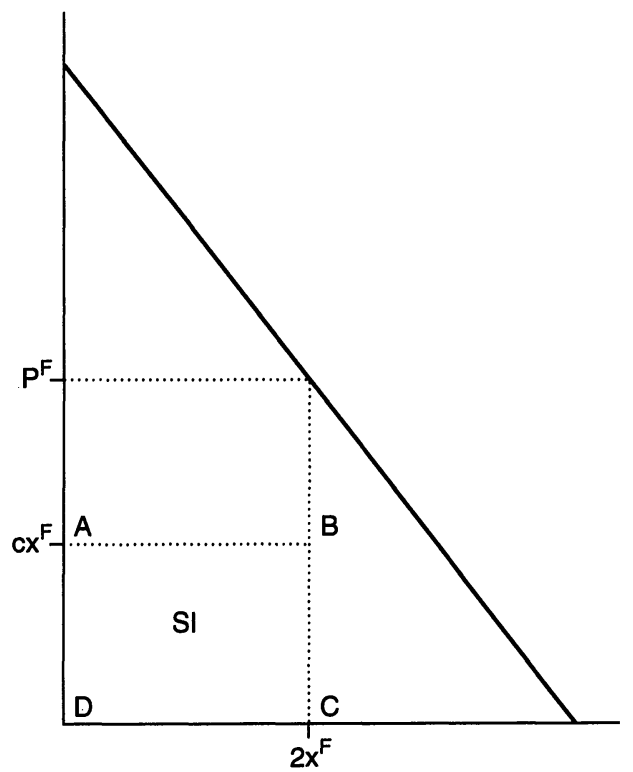

FIGURE 1. SWL with diversified firms.

cost $S$ incurred by each firm. In addition to the standard SWL triangle $\Delta^{F}$ in each market, there is the rectangular area $A B C D$ reflecting the strategic inefficiency (SI) arising from diseconomies of scale leading to average variable costs exceeding zero, plus the purchase price of the flexible technology $S$. Let us turn first to the welfare loss triangle $\Delta^{F}$ in each market. This is equal to $\left(P^{F}\right)^{2} / 2$ in each market, so that over both markets $\Delta^{F}=\left(P^{F}\right)^{2}$, which from (7b) is given by

$$
\Delta^{F}(c)=(1+c)^{2} A^{2} /(3+c)^{2} .
$$

As $c$ gets larger, diseconomies of scope increase so that outputs fall and prices rise, thus increasing the welfare loss. When $c=1, \Delta^{F}(1)=1 / 4$, which is equal 
to the pure-monopoly welfare loss, since $P^{F}(1)=P^{M}$. Turning to the strategic inefficiency, this is given in total by

$$
S I=c\left(x_{1}^{F} y_{1}^{F}\right)+c\left(x_{2}^{F} y_{2}^{F}\right)=2 c A^{2} /(3+c)^{2} .
$$

If we put together these two sources of welfare loss and $S$ per firm, we have the total:

$$
S W L^{F}=A^{2}\left(1+c^{2}+4 c\right) /(3+c)^{2}-2 S .
$$

Note that both $S I$ and the total $S W L^{F}$ are increasing in $c$. If we compare this to the pure monopoly outcome $\Delta^{M}=A^{2} / 4$, then there will be a range of values of $c$ for which $S W L^{F}$ exceeds the monopoly welfare loss. Let us take the case where the flexible technology is free: then we can find the critical value of $c^{*}$ at which the two losses are equal:

$$
\begin{aligned}
\Delta^{M} & =S W L^{F} \\
A^{2} / 4 & =A^{2}\left(1+c^{2}+4 c\right) /(3+c)^{2} .
\end{aligned}
$$

Hence:

$$
c^{*}=\left[(160)^{1 / 2}-5\right] / 6=0.442 \quad(3 \text { d.p. }) \text {. }
$$

For $c<c^{*}$, the diversified outcome gives a better outcome than the pure-monopoly outcome: for $c^{*}<c<2$ the ranking is reversed. Clearly, if there are strictly positive lump-sum costs associated with the flexible technology, the flexible outcome can be worse for lower values of $c$.

How does the total welfare loss break down into its components, the welfare triangle loss $\Delta^{F}$ and $S I$ ? In Table 1 we compute these values for three representative values of $c$. As can be seen, the size of the welfare loss due to productive

TABLE 1

A Comparison of the Welfare loss ARISING FROM STRATEGIC INEFFICIENCY AND THE RESTRICTION OF OUTPUT IN A DIVERSIFIED DUOPOLY

\begin{tabular}{llll}
\hline \multicolumn{1}{c}{$c$} & \multicolumn{1}{c}{$\Delta^{F}$} & $S I(c)$ & \multicolumn{1}{c}{$S W L^{F}$} \\
\hline $0 \cdot 25$ & 0.148 & 0.047 & 0.195 \\
0.50 & 0.184 & 0.082 & 0.266 \\
0.75 & 0.218 & 0.107 & 0.325 \\
\hline
\end{tabular}

Notes: derived from (9) and (10) under the assumption that $A=1$ and $S=0$, to 3 d.p. For these values, $\Delta^{M}=$ 0.25 .

inefficiency is not small relative to the standard welfare loss triangle: for $0.25 \leq c \leq 0.75$, the former is between a third and a half of the latter. If we include the lump-sum element $2 S$, then clearly the strategic inefficiency is even more important.

\section{ACKNOWLEDGMENTS}

I would like to thank two anonymous referees for their invaluable comments. Faults remain my own. 


\section{NOTES}

1. See, inter alia, Andrews (1949), Berry (1974-5), Brunner (1961), Lambkin (1988). This has been particularly emphasized by proponents of contestability theory (see Baumol 1982), who focus on the role of 'hit-and-run' entry as a discipline on incumbent firms.

2. The term 'flexibility' has different usages. In the literatures on uncertainty and strategic precommitment, 'flexibility' has to do with the slope of the MC curve for a single output. (See Dixon (1986) for a discussion and references.) We use theterm to relate to the ease of producing more types of outputs as opposed to less.

3. This paper will concentrate solely on externalities across markets on the cost side. For studies of multi-market oligopoly that concentrate on the demand-side linkages, see papers by Bernheim and Whinston (1990) and Shaked and Sutton (1990).

4. The variable cost element $c\left(x_{i} y_{i}\right)$, could be expanded to a more general quadratic form such as $c\left(x_{i}+y_{i}\right)^{2}$, and the dedicated technology could itself be quadratic (e.g. $c x_{1}^{2}$ and $\left.c x_{2}^{2}\right)$. In this case the diseconomies of scope would stem from diminishing returns. This interpretation would be particularly relevant as a model of inter-industry trade. The form adopted (2) focuses on the interactive term, and this does not alter the qualitative results.

5. The original definition given in Panzar and Willig (1981) relates to sub-additivity of the cost function, rather than cross-derivatives on the cost function. The two definitions are not directly related owing to fixed costs. The Bulow et al. (1985) definition is more directly relevant for this paper since it relates directly to marginal cost, and hence to the firms' reaction functions.

\section{REFERENCES}

ANDrews P. W. S. (1949). Manufacturing Business. London: Macmillan.

BAILEY, E. and Friedlander, A. (1982). Market structure and multiproduct industries. Journal of Economic Literature, 20, 1024-48.

BAumol, W. (1982). Contestable markets. American Economic Review, 72, 1-15.

$\rightarrow$ Bernheim, B. D. and Whinston, M. D. (1990). Multimarket contact and collusive behaviour. Rand Journal, 21, 1-26.

BERRY, C. H. (1974-5). Corporate diversification and market structure. Bell Journal of Economics and Management Science, 4, 196-204.

Brander, J. and Eaton, J. (1984). Product line rivalry, American Economic Review, 74, 323-34.

Bulow, J., Geanakopoulos, J. and Klemperer, P. (1985). Multimarket oligopoly: strategic substitutes and complements. Journal of Political Economy, 93, 488-511.

BRUNNer, E. (1961). A note on potential competition, Journal of Industrial Economics, 9, 248 50.

Cairns, R. and MAhabir, D. (1988). Contestability: a revisionist view. Economica, 55, 269-76.

CALEM, P. (1988). Entry and entry deterrence in penetrable markets. Economica, 55, 171-84.

Dixon, H. (1986). Strategic investment with consistent conjectures. Oxford Economic Papers, 38, 111-28.

EAton, B. and Lemche, S. (1991). The geometry of supply, demand, and competitive market structure with economies of scope. American Economic Review, 81, 901-11.

LAMBKIN, M. (1988). Order of entry and performance in new markets. Strategic Management Journal, 9, 127-40.

Milgrom, P. and RoberTs, J. (1990). The economics of modern manufacturing: technology, strategy and organization. American Economic Review, 80, 511-28.

Murfin, A. (1982). Monopoly and competition: a theoretical and empirical application to the UK car industry. PHD thesis, London University.

Panzar, J. and Willig, R. (1981). Economics of Scope. American Economic Review, Conference Supplement, 268-72.

Roller, L. and TOMвак, M. (1990). Strategic choice of flexible production technologies and welfare implications. Journal of Industrial Economics, 38, 417-32.

$\rightarrow$ ShaKed, A. and Sutton, J. (1990). Multiproduct firms and market structure. Rand Journal, 21, $45-62$. 